\title{
Unfulfilled potential of primary care in Europe
}

The Alma Ata declaration's compelling vision of health for all will not be realised until we take community level prevention seriously, argue Luke Allen and colleagues

\author{
Luke N Allen GP academic clinical fellow ${ }^{1}$, Shannon Barkley technical officer ${ }^{2}$, Jan De Maeseneer \\ emeritus professor ${ }^{3}$, Chris van Weel emeritus professor of general practice ${ }^{45}$, Hans Kluge director ${ }^{6}$, \\ Niek de Wit professor ${ }^{7}$, Trisha Greenhalgh professor $^{1}$
}

\begin{abstract}
${ }^{1}$ Nuffield Department of Primary Care Health Sciences, University of Oxford, UK; ${ }^{2}$ Primary Healthcare Services, WHO, Geneva; ${ }^{3}$ Department of Family Medicine and Primary Health Care, Ghent University, Belgium; ${ }^{4}$ Radboud Institute of Health Sciences, Department of Primary and Community Care, Radboud University, Nijmegen, Netherlands; ${ }^{5}$ Department of Health Services Research and Policy, Australian National University, Canberra, Australia; ${ }^{6}$ Division of Health Systems and Public Health, WHO Europe, Copenhagen, Denmark ; ${ }^{7}$ Department of General Practice, Julius Center for Health Sciences and Primary Care, University Medical Center Utrecht, Netherlands
\end{abstract}

To mark the 40th anniversary of the Alma Ata declaration on primary healthcare in October $2018,{ }^{1}$ world leaders gathered in Astana to renew their commitment to health for all. Although primary healthcare is about much more than primary care services, getting this element right is crucial to supporting the overarching principles of equity, population level primary prevention, and action on the social determinants of health. In the context of increasing chronic multimorbidity and ageing populations we consider why European primary care has broadly failed to engage with the prevention oriented approach set out 40 years ago, and what conditions are required to realise its potential.

\section{Contemporary challenges in primary care}

Primary care has been defined as "first-contact, continuous, comprehensive, and coordinated care provided to populations undifferentiated by gender, disease, or organ system." ${ }^{2}$ A stronger primary care sector is associated with greater equity, better health outcomes, and, in some settings, lower overall costs. ${ }^{34}$ Primary care can manage $90 \%$ of all health system interactions, making it central to the realisation of universal health coverage. ${ }^{56}$ Over recent decades, improvements in the quality and coverage of primary care have delivered important population health gains around the world. ${ }^{37-12}$

Primary care teams are commonly led by family doctors (also known as general practitioners or family practitioners), who have received postgraduate specialty training to provide comprehensive family and community oriented medical care. In recent decades they have come under pressure from substantial increases in workload, including paperwork and delegation of care from hospitals to the community setting. ${ }^{613}$ Task shifting to primary care is often appropriate, but reallocation of responsibility is rarely followed by adequate reallocation of resources. ${ }^{13}$ Primary care teams have been on the front lines of this century's major demographic and epidemiological challenges, including ageing, socioeconomic inequalities, chronic diseases, rising consultation rates, and multimorbidity. ${ }^{13-15}$ The future sustainability of our health systems depends on primary care successfully meeting increased need with affordable, person centred, high quality care.

By shifting the emphasis of primary care from treatment towards proactive care, prevention, and health promotion at the local population level, it may be possible to deal with health challenges at an earlier stage.

This idea is not new; in fact it is the central thesis of the Alma Ata declaration, which set out to distinguish primary healthcare (box 1) from the status quo of care oriented around sickness. Although moving towards more proactive primary healthcare requires the collective actions of policy makers, communities, and many different health professionals, the primary care sector is uniquely invested with the legitimacy and authority to lead this change. 


\section{Box 1: Article VII of the 1978 Alma Ata declaration}

\section{Primary healthcare}

- Reflects and evolves from the economic conditions and sociocultural and political characteristics of the country and its communities and is based on the application of the relevant results of social, biomedical, and health services research and public health experience

- Addresses the main health problems in the community, providing promotive, preventive, curative, and rehabilitative services accordingly

- Includes at least education concerning prevailing health problems and the methods of preventing and controlling them; promotion of food supply and proper nutrition; an adequate supply of safe water and basic sanitation; maternal and child healthcare, including family planning; immunisation against the major infectious diseases; prevention and control of locally endemic diseases; appropriate treatment of common diseases and injuries; and provision of essential drugs

- Involves, in addition to the health sector, all related sectors and aspects of national and community development, in particular agriculture, animal husbandry, food, industry, education, housing, public works, communications, and other sectors and demands the coordinated efforts of all those sectors

- Requires and promotes maximum community and individual self reliance and participation in the planning, organisation, operation, and control of primary healthcare, making fullest use of local, national, and other available resources, and to this end develops through appropriate education the ability of communities to participate

- Should be sustained by integrated, functional, and mutually supportive referral systems, leading to the progressive improvement of comprehensive healthcare for all and giving priority to those most in need

- Relies, at local and referral levels, on health workers, including physicians, nurses, midwives, auxiliaries, and community workers as applicable, as well as traditional practitioners as needed, suitably trained socially and technically to work as a health team and to respond to the expressed health needs of the community.

Primary care systems are currently configured around sequentially consulting unwell individuals, but many of the current challenges in health require upstream action. Population level interventions ${ }^{16}$ tackle environmental risk factors as well as social and economic determinants of health. Community level interventions include investment in green spaces, housing, active transport networks, smoke-free zones, traffic calming measures, and local licensing and zoning regulations.

Many practices are taking first steps towards dealing with social determinants through social prescribing. However, this is an individual level approach rather than seeking to influence structural or system determinants that affect whole subpopulations.

Policy makers may be reluctant to invest in pivoting primary care systems towards population prevention for numerous reasons. It is much easier to blame individuals for making poor lifestyle choices than it is to change the environment; prevention and health system reforms require upfront political and capital investment but the benefits are invariably conferred to political successors; it is hard to take credit for things that haven't happened (such as deaths averted); and it is difficult to obtain robust evidence for the effectiveness of population level interventions within the current evidence model. Policy makers also face complex trade-offs between investing in prevention versus other elements of the universal health coverage and primary healthcare agendas, such as improving access to services.

\section{Structural determinants}

In many European countries the remit of primary care extends only as far as diagnosing and treating disease in individuals (and only those with the means and motivation to seek care). ${ }^{17}$ Although patients may be opportunistically screened for hypertension or offered support with smoking cessation, there is often no systematic approach to engaging with the broader health determinants at the community level. ${ }^{18}$

This is a lost opportunity. In concert with public health teams, primary care teams are well positioned to identify the local drivers of morbidity and mortality, including transport, the food environment, pollution, poverty, early years education, housing, road safety, exercise spaces, and the availability and affordability of alcohol and tobacco. These non-medical factors are responsible for up to $90 \%$ of health outcomes. ${ }^{19}$ Primary care teams see these local social determinants at work every day ${ }^{20}$ and have overlapping moral, professional, and (where they are paid by capitation) financial interests in tackling them.

Through collaboration with public health, social care, and other community organisations, primary care professionals are uniquely placed to translate their insights into priorities for community level prevention. Primary care teams have detailed patient datasets and a unique ecobiopsychosocial perspective, and they often develop a high stock of community trust and a rich ethnographic understanding of the local population. ${ }^{21}$ Although the Alma Ata declaration called for population level prevention to become the central organising activity of primary healthcare, teams that operate this way remain rare.

\section{Restricted remit}

Early general practitioners such as William Pickles and Frans Huijgen felt responsible for population and individual level practice, ${ }^{22}$ but the role of contemporary primary care teams is much narrower in many European countries. ${ }^{1123-25}$ Sutchfield and colleagues argue that an overemphasis on specialisation and the evolving professionalisation of primary care and public health as distinct specialties during the 20th century led to GPs eschewing public health roles. ${ }^{26}$ Primary care came to focus more on biomedical curative services for individuals and developed its own set of definitions around population health. ${ }^{27}$ Recent efforts to bring the two isolated specialties back into alignment have been under-resourced and often meet resistance from powerful doctors' organisations. ${ }^{28}$

Financing has also played a large role. Once ubiquitous fee-for-service systems can lead to the underuse of preventive services, ${ }^{290}$ and it is difficult to make people contribute to action on the social determinants as the benefits are a "public good" (that is, one person benefitting does not reduce the benefit for others and no-one can be excluded. $)^{31}$ The international move to capitation has helped provide capital for investment in primary prevention at the community level, but growing multimorbidity often seems to absorb any additional money, as in the UK. ${ }^{132}$ Governments tend to govern and finance public health and primary care functions separately, and insurance companies have been reluctant to pay for community prevention delivered through primary care. ${ }^{33}$

The degree to which primary care teams engage with even basic individual preventive activity varies widely across Europe, with variation underpinned by differing financing arrangements. ${ }^{1123} 3435$ Experience from other continents shows that state regulators often restrict the practice of primary care professionals to individual level functions and disproportionately direct regulatory measures to public sector practices (which may be more likely to consider public health than their private counterparts). ${ }^{836}$

Anecdotally, our primary care colleagues believe that social determinants simply aren't their responsibility, even though they appreciate that these issues affect their work. And can we blame them when modern primary care teams are not trained, 
paid, held accountable, or given time for delivering community level prevention ? $^{37}$

\section{Realising the potential of primary care}

We have argued that European primary care teams are well positioned to assess and tackle structural determinants of health at the community level, but what does this look like in practice?

The Hedena Health GP practice in Oxford has worked with housing developers, the city council, public health teams, and NHS England to develop a health promoting housing development in a deprived area. The "healthy new town" gives primacy to cyclists, pedestrians, and public transport as well as focusing on social inclusion, safe housing, and the food environment. $^{3839}$

In Belgium, the Botermarkt Community Health Centre in Ghent has led several preventive initiatives prompted by assessment of the local population's health needs. These have included leading a coalition of community stakeholders to redesign a dangerous road section and successfully lobbying the council for a new playground. These activities have helped to reduce road traffic injuries and childhood obesity. ${ }^{2140}$

The "deep end" practices serving deprived areas inGlasgow and Clyde work closely with members of the local community to assess and reduce local drivers of disease through initiatives like walking groups, financial advice, community gardens, and supporting the reforestation of disused land. Recognising that tackling social problems can reduce demand by improving health outcomes, Garscadden Burn medical practice closes one afternoon a month to train staff in this area. ${ }^{41} 42$

Primary care professionals in the Dutch city of Utrecht work with community nurses and social workers to deliver a city-wide programme that supports frail elderly people, identified using routine primary care data. ${ }^{43}$

\section{System recalibration}

Certain conditions are required to facilitate this style of working, starting with financing. The Botermarkt practice successfully lobbied for capitated payment, which they used to employ a community health worker to engage with issues like housing, playgrounds, street lighting, healthy food availability, and active transport. ${ }^{214}$ England and Estonia's quality bonus schemes could be modified to encourage action at the local population level.

Moving away from fee-for-service and towards mixed payment models that include population based weighted capitation is important for sustainability and encouraging population based practice. ${ }^{21456}$ More important is ensuring that the primary care sector is adequately financed. Even in countries like the UK, where primary care is well developed and delivers over $90 \%$ of all health system interactions, primary care receives around 10\% of government health spending. ${ }^{47}$ Many of our English primary care colleagues believe that this is not enough to provide a bare bones individual level service, let alone expand to include social determinants. Long time horizons are required to realise the gains of investing in primary prevention.

Empanelment is a second prerequisite as primary care teams need to know who they are serving and the characteristics of their patient population. ${ }^{48}$ Staff also need better training on how to identify and deal with social determinants, complemented by easy access to public health specialists. Deeper integration can be achieved through co-location, regular meetings, and shared information systems, work plans, and budgets. ${ }^{32}$ Qualitative and quantitative primary care data should be used routinely to develop public health interventions. ${ }^{49}$

Scotland ${ }^{50}$ and Catalonia ${ }^{51}$ have tried to improve the coordination of multiple health and social care services around the needs of patients and populations. This integrated working allows primary care teams to engage directly with agencies working on social determinants of health. ${ }^{52}$

Finally, a cultural shift is required within modern medicine, from specialist hospital treatment to community led prevention and care. The NHS Five Year Forward View ${ }^{53}$ and Astana declaration $^{54}$ are good examples of policy commitment to prevention oriented care. Medical associations carry enormous weight and will need to catch the vision of what primary care can accomplish for patients when their sphere of concern enlarges to encompass more than consultation rooms. Commissioners and individual practitioners also need to be convinced that this enlarged scope is good for their patients. ${ }^{55}$ Box 2 outlines a few suggested enablers of reform.



\section{Time for action}

Primary care teams provide invaluable medical care for individuals, and this will always be required. However, they 
are also well positioned to help identify and influence the local social determinants that make their patients ill. Given that primary care workers are not currently trained, paid, or managed to think about community drivers of disease, it is not surprising that this approach is rare. Policy makers in Astana talked the talk, recommitting to orienting health systems around prevention. Introducing empanelment, population weighted capitation, enhanced training, unified budgets, and intersectoral working arrangements would show that they are willing to walk the walk.

\section{Key messages}

The 1978 Alma Ata declaration called for a shift in focus from reactively managing sick individuals to prevention and health promotion at community level

Increasing chronic multimorbidity and rising demand make preventive action more pertinent, yet the Alma Ata vision remains unrealised

Most primary care systems constrain rather than facilitate engagement with local public health teams, communities, and initiatives to tackle social determinants

Primary care financing, training, organisational structures, and incentives can and should be better aligned with community level prevention

Contributors and sources: This manuscript was conceived by LNA, who drafted the original manuscript. SB, JDM, CVW, HK, NDW, and TG provided feedback, revised subsequent manuscripts, and reviewed the final version. Amanda Howe and Maureen Baker provided comments on the first draft. Kawaldip Sehmi reviewed the draft manuscript and commented on the final version. All authors are academic GPs with considerable experience. LNA is a WHO consultant working on the integration of primary care and public health and an editorial board member at the British Journal of General Practice. SB led the WHO preparations for the Alma Ata renewal. JDM is the chair of the European Commission's expert panel on effective ways of investing in health. CVW served on the Lancet international advisory board and is a former president of the World Organisation of Family Doctors (WONCA). $\mathrm{HK}$ is a senior director at WHO Europe working on health systems and public health. NDW has held several senior international advisory roles in primary care. TG is a leading international primary care academic.

Competing interests: We have read and understood BMJ policy on declaration of interests and have no relevant interests to declare.

Provenance and peer review: Not commissioned; externally peer reviewed.

1 World Health Organization, Unicef. Declaration of Alma-Ata international conference on primary health care, Alma-Ata, USSR, 6-12 September 1978.

2 Starfield B. Is primary care essential? Lancet 1994;344:1129-33.

10.1016/S0140-6736(94)90634-3 7934497

3 Starfield B, Shi L, Macinko J. Contribution of primary care to health systems and health. Milbank Q 2005;83:457-502. 10.1111/j.1468-0009.2005.00409.x 16202000

4 Kringos DS, Boerma W, van der Zee J, Groenewegen P. Europe's strong primary care systems are linked to better population health but also to higher health spending. Health Aff (Millwood) 2013;32:686-94. 10.1377/hlthaff.2012.1242 23569048

5 Stigler FL, Macinko J, Pettigrew LM, Kumar R, van Weel C. No universal health coverage without primary health care. Lancet 2016;387:1811.

10.1016/S0140-6736(16)30315-4 27203497

6 Hobbs FDR, Bankhead C, Mukhtar T, etal. National Institute for Health Research School for Primary Care Research. Clinical workload in UK primary care: a retrospective analysis of 100 million consultations in England, 2007-14. Lancet 2016;387:2323-30 10.1016/S0140-6736(16)00620-6 27059888

7 Caley M. Remember Barbara Starfield: primary care is the health system's bedrock. BMJ 2013:347:f4627. 10.1136/bmj.f4627 23900532

8 van Weel C, Kassai R, Qidwai W, etal . Primary healthcare policy implementation in South Asia. BMJ Glob Health 2016;1:e000057. 10.1136/bmjgh-2016-000057 28588938

9 Rohde J, Cousens S, Chopra M, etal . 30 years after Alma-Ata: has primary health care worked in countries? Lancet 2008;372:950-61. 10.1016/S0140-6736(08)61405-1 18790318

10 Macinko J, Starfield B, Shi L. The contribution of primary care systems to health outcomes within Organization for Economic Cooperation and Development (OECD) countries, 1970-1998. Health Serv Res 2003;38:831-65. 10.1111/1475-6773.00149 12822915

11 Lember M, Cartier T, Bourgueil Y, Dedeu T. Structure and organization of primary care. In: Kringos D, Boerma W, Hutchinson A, Saltman RB, eds. Building primary care in a changing Europe. (Observatory Studies Series 38). Eur Obs Heal Syst Policies, 2015 172.

12 Schäfer WLA, Boerma WGW, Kringos DS, etal . Measures of quality, costs and equity in primary health care instruments developed to analyse and compare primary care in 35 countries. Qual Prim Care 2013;21:67-79.23735688

13 Baird B, Charles A, Honeyman M, Maguire D, Das P. Understanding pressures in general practice. King's Fund. 2016.https://www.kingsfund.org.uk/sites/default/files/field/field publication_file/Understanding-GP-pressures-Kings-Fund-May-2016.pdf
14 Barnett K, Mercer SW, Norbury M, Watt G, Wyke S, Guthrie B. Epidemiology of multimorbidity and implications for health care, research, and medical education: a cross-sectional study. Lancet 2012;380:37-43. 10.1016/S0140-6736(12)60240-2 22579043

15 Crisp N, Stuckler D, Horton R, etal . Manifesto for a healthy and health-creating society. Lancet 2016;388:e24-7. 10.1016/S0140-6736(16)31801-3 27726950

16 Rose G. Sick individuals and sick populations. Int J Epidemiol 1985;14:32-8. 10.1093/ije/14.1.32 3872850

17 World Health Organization. 2008 World Health Report: Primary care: now more than ever. 2008. http://www.who.int/whr/2008/whr08_en.pdf

18 Marmot M, Friel S, Bell R, Houweling TA, Taylor SCommission on Social Determinants of Health. Closing the gap in a generation: health equity through action on the social determinants of health. Lancet 2008;372:1661-9. 10.1016/S0140-6736(08)61690-6 18994664

19 The relative contribution of multiple determinants to health outcomes. Health Aff Health Policy Brief 2014 Aug 21. https://www.healthaffairs.org/do/10.1377/hpb20140821.404487/ full/

20 Senior T. How chronic diseases thrive. Br J Gen Pract 2018;68:387 10.3399/bjgp18X698237 30049774

21 De Maeseneer J. Family medicine and primary care: at the crossroads of societal change. Tielt: Lannoo campus, 2017

22 Watt G. William Pickles lecture. General practice and the epidemiology of health and disease in families. Br J Gen Pract 2004;54:939-44.15588541

23 Pelone F, Kringos DS, Spreeuwenberg P, De Belvis AG, Groenewegen PP. How to achieve optimal organization of primary care service delivery at system level: lessons from Europe. Int J Qual Health Care 2013;25:381-93. 10.1093/intghc/mzt020 23407822

24 de Waard AM, Hollander M, Korevaar JC, etal. SPIMEU Project Group. Selective prevention of cardiometabolic diseases: activities and attitudes of general practitioners across Europe. Eur J Public Health 2018. 10.1093/eurpub/cky112 30016426

25 World Health Organization. 2008 World health report: primary care: now more than ever. 2008. http://www.who.int/whr/2008/whr08_en.pdf

26 Scutchfield FD, Michener JL, Thacker SB. Are we there yet? Seizing the moment to integrate medicine and public health. Am J Public Health 2012;102(Suppl 3):S312-6. 10.2105/AJPH.2012.300724 22690964

27 Gourevitch MN, Cannell T, Boufford JI, Summers C. The challenge of attribution: responsibility for population health in the context of accountable care. Am J Prev Med 2012;42(Suppl 2):S180-3. . 10.1016/j.amepre.2012.03.012 22704435

28 Koo D, Felix K, Dankwa-Mullan I, Miller T, Waalen J. A call for action on primary care and public health integration. Am J Public Health 2012;102(Suppl 3):S307-9. 10.2105/AJPH.2012.300824 22690962

29 Sebo P, Cerutti B, Fournier JP, etal . How do general practitioners put preventive care recommendations into practice? A cross-sectional study in Switzerland and France. BMJ Open 2017;7:e017958. 10.1136/bmjopen-2017-017958 28988186

30 National Institutes of Health. Changing landscape: from fee-for-service to value-based reimbursement. 2018. https://www.niddk.nih.gov/health-information/communicationprograms/ndep/health-professionals/practice-transformation-physicians-health-care-teams/ why-transform/changing-landscape-fee-service-value-based-reimbursement

31 Nichols LM, Taylor LA. Social determinants as public goods: a new approach to financing key investments in healthy communities. Health Aff (Millwood) 2018;37:1223-30. 10.1377/hlthaff.2018.0039 30080474

32 Allen L. Leveraging primary care to address social determinants. Lancet Public Health 2018;3:e466. 10.1016/S2468-2667(18)30186-5 30314589

33 De Maeseneer J, Willems S, De Sutter A, Van de Geuchte I, Billings M. Primary health care as a strategy for achieving equitable care: a literature review commissioned by the Health Systems Knowledge Network. 2007. https://biblio.ugent.be/publication/396406

34 Kringos D, Boerma W, Bourgueil $\mathrm{Y}$, etal . The strength of primary care in Europe: an international comparative study. Br J Gen Pract 2013;63:e742-50. 10.3399/bjgp13X674422 24267857

35 de Waard AM, Wändell PE, Holzmann MJ, etal. SPIMEU Research Group. Barriers and facilitators to participation in a health check for cardiometabolic diseases in primary care: A systematic review. Eur J Prev Cardiol 2018;25:1326-40. 10.1177/2047487318780751 29916723

36 van Weel C, Alnasir F, Farahat T, etal . Primary healthcare policy implementation in the Eastern Mediterranean region: Experiences of six countries. Eur J Gen Pract 2018:24:39-44. 10.1080/13814788.2017.1397624 29168411

37 Primary Health Care Performance Initiative. The measurement gap. https://improvingphc. org/measuring-phc

38 Grosvenor Developments. Health new towns: Barton Park. http://www.oxfordshireccg. nhs.uk/documents/localities/oxford-city/documents/barton-healthy-new-town-presentation. pdf

39 NHS England. Barton. https://www.england.nhs.uk/ourwork/innovation/healthy-new-towns/ barton-park/

40 De Roo L, De Maeseneer J. Community Health Centre Botermarkt: 35 years of implementation of the Alma Ata Declaration! http://www.wgcbotermarkt.be/eng/sites/ default/files/35\%20years\%20of\%20implementation\%20of\%20the\%20Alma\%20Ata\% 20Declaration 0.pdf

41 Watt G, Brown G, Budd J, etal . General practitioners at the deep end: the experience and views of general practitioners working in the most severely deprived areas of Scotland. Occas Pap R Coll Gen Pract 2012;(89):i-40.27074888

42 GPs at the Deep End. Deep end report 32: 8 years of the Deep End Project. 2017. https: //www.gla.ac.uk/media/media_557259_en.pdf

43 NOEL. Nijmegen region on the same line (NOEL) [In Dutch]. 2018. https://www. regionijmegenopeenlijn.nl/

44 Allen L. Primary care 2.0. PLoS global health blog. 9 Oct 2018. https://blogs.plos.org/ globalhealth/2018/10/primary-care-2-0/

45 Sessums LL, Conway PH. Saving primary care. JAMA Intern Med 2017;177:1560-2. 10.1001/jamainternmed.2017.4991 28973167

46 Health OECD. Policy studies. better ways to pay for health care. OECD, 2016.

47 British Medical Association. Funding general practice in England. BMA, 2017.

48 Grumbach K, Olayiwola JN. Patient empanelment: the importance of understanding who is at home in the medical home. J Am Board Fam Med 2015;28:170-2. 10.3122/jabfm.2015.02.150011 25748755

49 Murray SA, Tapson J, Turnbull L, McCallum J, Little A. Listening to local voices: adapting rapid appraisal to assess health and social needs in general practice. BMJ 1994;308:698-700. 10.1136/bmj.308.6930.698 8142796 
50 Bruce D, Parry B. Integrated care: a Scottish perspective. London J Prim Care (Abingdon) 2015;7:44-8. 10.1080/17571472.2015.11494376 26217405

51 Contel JC, Ledesma A, Blay C, etal . Chronic and integrated care in Catalonia. Int J Integr Care 2015;15:e025. 10.5334/ijic.2205 26150763

52 van Weel C, De Maeseneer J, Roberts R. Integration of personal and community health care. Lancet 2008;372:871-2. 10.1016/S0140-6736(08)61376-8 18790296

53 NHS England. Five year forward view. https://www.england.nhs.uk/wp-content/uploads/ 2014/10/5yfv-web.pdf
54 World Health Organization. Declaration of Astana [draft]. 2018. http://www.who.int/primaryhealth/conference-phc/DRAFT_Declaration_on_Primary_Health_Care_28_June 2018. pdf

55 Allen LN, Barry E, Gilbert C, Honney R, Turner-Moss E. From reactive to proactive: how to move from managing sick individuals to creating healthy communities. Br J Gen Pract [forthcoming].

Published by the BMJ Publishing Group Limited. For permission to use (where not already granted under a licence) please go to http://group.bmj.com/group/rights-licensing/ permissions 